\title{
Severe cardiac anomalies in sibs with Larsen syndrome
}

\author{
P STRISCIUGLIO*, G SEBASTIO*, G ANDRIA*, S MAIONE†, AND \\ V RAIA*
}

From *the Department of Pediatrics and the Department of Internal Medicine, 2nd Faculty of Medicine, University of Naples, Italy.

SUMMARY Larsen syndrome is characterised by congenital anterior dislocation of the knees, associated with other joint dislocations, and a characteristic facies. Autosomal recessive and dominant inheritance have been proposed. A brother and a sister with consanguineous parents, suggesting autosomal recessive inheritance, were found to have the typical features of Larsen syndrome. In addition, they had severe cardiac manifestations, never reported before in familial cases of the syndrome. We suggest that the recessive form is probably more severe than the dominant form because of the frequent presence of concomitant cardiac anomalies.

\section{Case reports}

CASE 1

The proband was a 2-month-old female, born to a G4, P3, A0 37-year-old woman, after an uncomplicated term pregnancy. There was no exposure to any known teratogenic agents during pregnancy. Delivery was uncomplicated and spontaneous. Her birth weight was $2500 \mathrm{~g}$ and her length was $47 \mathrm{~cm}$. At birth she was noted to have bilateral congenital dislocation of the knees and a right club foot. Surgical reduction of the knees was performed at the age of 20 days. At 2 months of age, she was admitted to our hospital because of growth failure. The parents were healthy. Family history revealed that the maternal grandmother and the father of the proband were first cousins. Two older sisters of the patient were normal and her brother had died at 2 years 6 months (see case 2). There was no family history of other congenital malformations.

On admission at 2 months of age physical examination revealed a girl with dysmorphic features. Her weight was $3750 \mathrm{~g}$ ( $<5$ th centile), length $49.5 \mathrm{~cm}$ ( $<5$ th centile), and head circumference $37 \mathrm{~cm}$ (10th centile). She had a prominent forehead, depressed nasal bridge, wide set eyes, proptosis, and blue sclerae (fig 1). Broad spatulate thumbs and short fingernails were present. Dermatoglyphic analysis revealed bilateral simian lines on the palms and four ulnar loops and six whorls on the fingertips.

Received for publication 21 January 1983. Accepted for publication 19 April 1983.

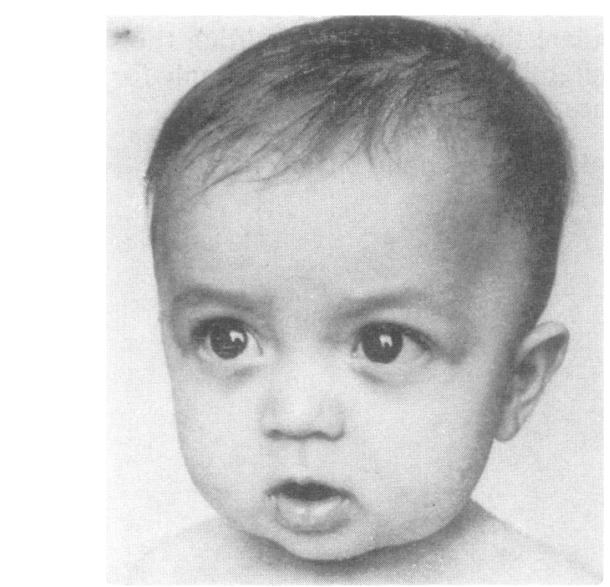

FIG 1 Case 1 at the age of 8 months.

Pectus carinatum, mild lumbar scoliosis, and left inguinal hernia were noted. The cardiovascular system was normal. Fundoscopy was also normal. Development was within normal limits. $X$-ray examination of the skeletal system showed bilateral dislocation of the hips, elbows, and knees, in addition to right club foot. Supernumerary carpal bones were also noted. Chromosome analysis revealed a normal female karyotype. She was doing relatively well until 19 months of age, when a chest $x$-ray showed a globular cardiac silhouette. Auscultation revealed normal first and second heart sounds. Peripheral 
pulses and systolic pressure were normal. Tachycardia $(160 / \mathrm{m})$ was present. The electrocardiogram suggested enlargement of the right atrium. Monodimensional echocardiogram showed that the right ventricle was markedly enlarged (fig 2 ) (telediastolic diameter $3 \mathrm{~cm}$, normal values 0.3 to $1.3 \mathrm{~cm}$ ) with minimal hypertrophy $(0.4 \mathrm{~cm})$ of the anterior wall. A slightly dilated aortic root $(1.6 \mathrm{~cm}$, normal values 0.7 to $1.5 \mathrm{~cm}$ ) was also present. Although the clinical diagnosis of pulmonary stenosis was made, the parents refused permission for invasive cardiac studies. Four months later the patient was admitted to another hospital where she died of heart failure.

\section{CASE 2}

During our investigation of the proband, the family history revealed that her older brother had been similarly affected and had died aged $2 \frac{1}{2}$ years. He was 8 months old when he was admitted to another hospital for evaluation of failure to thrive. He was born after an uncomplicated term pregnancy to a G3, P2, A0 30-year-old woman. Delivery was uncomplicated and spontaneous. His birth weight was $3000 \mathrm{~g}$. Physical findings obtained from photographs and hospital records revealed typical facial features similar to those found in his sister (fig 3). He also had pectus carinatum, right club foot, and left inguinal hernia. The cardiovascular system was apparently normal at 8 months of age. $X$-ray examination revealed bilateral dislocation of the knees, lumbar scoliosis, and supernumerary carpal bones. A diagnosis of cyanotic congenital heart disease was made at 2 years of age. Three months later the patient was admitted to a different hospital in a critical condition. The diagnosis of mitral insufficiency secondary to endocardial fibroelastosis

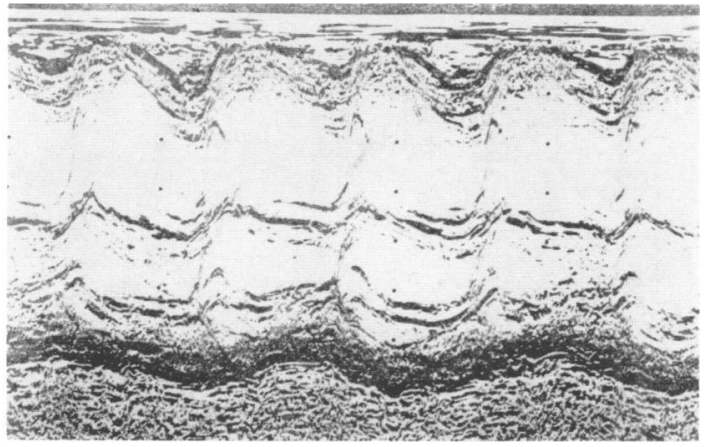

FIG $2 M$ mode echocardiogram of the left and right ventricle of the proband with a simultaneous recording of both atrioventricular valves. The right ventricle shows a marked increase of internal diameter and a slight thickening of the anterior wall. The left ventricular measurements are within normal limits.

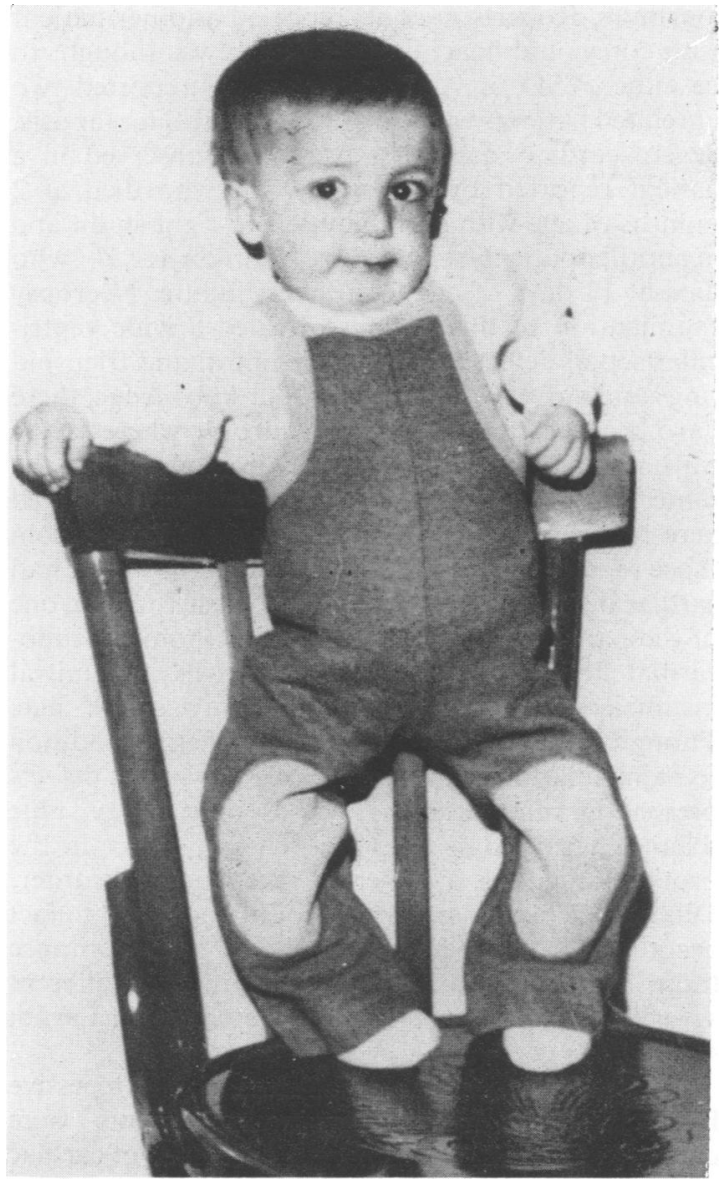

FIG 3 Case 2 at the age of 2 years.

was made. Unfortunately, cardiac catheterisation, angiocardiography, and echocardiography were not performed. Three months after admission the patient died of heart failure. Permission for necropsy was not granted by the parents.

\section{Discussion}

In 1950 Larsen et al ${ }^{1}$ described a new syndrome characterised by congenital dislocation of multiple joints and a typical facies. Although in the following years the syndrome became a well recognised clinical entity, it was only in 1975 that Swensonn et al ${ }^{2}$ pointed out the presence of cardiac anomalies in a patient who had a strikingly enlarged aortic root, in addition to classical features of the syndrome. They also noted that the original patient of Larsen et al ${ }^{1}$ and the patient reported by McFarland ${ }^{3}$ had cardiac 
murmurs. Robertson et $\mathrm{l}^{4}$ reported another patient with congenital heart disease, which was thought to be either VSD or ASD. Fauré et al ${ }^{5}$ reported two unrelated patients with cardiopathy without cyanosis. Severe cardiac anomalies were also observed in a patient reported by Renault et $a l^{6}$ who died at 2 months of age with dominant left to right shunt and in another patient, reported by Henrikson et al, ${ }^{7}$ who died at 13 days of age from heart failure. Necropsy examination of this patient revealed a wide ventricular septal defect involving the mitral and tricuspid rings and valves. To the best of our knowledge, there have been no reports of this syndrome where severe cardiac manifestations occurred in members of the same sibship. Furthermore, the proband reported here had cardiac anomalies probably different from those reported previously. Her brother, however, had cardiac defects probably similar to those found in one of the patients reported by Lee, ${ }^{8}$ in whom subendocardial fibrosis with subaortic stenosis and mitral insufficiency was diagnosed at $3 \frac{1}{2}$ years of age. Though the basic pathophysiology of this condition remains unknown, the nature of the various defects present in our patients, such as joint laxity, blue sclerae, hernia, and the type of heart defect in the brother, suggests a generalised collagen disorder. Different defects in collagen production could in fact account for the differing modes of inheritance (autosomal recessive and dominant) and the different severity of clinical presentation described in Larsen syndrome.

Our patients seem to be affected by the recessive form, since their consanguineous parents were clinically normal. In addition, the presence of cardiac anomalies in our family and in other patients reported, all with the recessive form, suggest that the recessive form is more severe than the dominant form. It was also suggested recently ${ }^{9}$ that the other anomalies, such as syndactyly, cleft palate, genital anomalies, and severe short stature, were found more frequently in the patients with the recessive form. Further reports are necessary to establish the incidence and the severity of cardiac anomalies in the recessive form of Larsen syndrome.

\section{References}

1 Larsen J, Schottstaedt EF, Bost FC. Multiple congenital dislocations associated with characteristic facial abnormality. J Pediatr 1950;37:574-81.

2 Swensonn RE, Linnebur AC, Paster SB. Striking aortic root dilatation in a patient with Larsen syndrome. J Pediatr 1975;86:914-5.

3 McFarland BL. Congenital dislocation of the knees. J Bone Joint Surg 1929;11:281-5.

4 Robertson FW, Kozlowski K, Middleton RW. Larsen's syndrome: three cases with multiple congenital join dislocations and distinctive facies. Clin Genet 1975;14 53-60.

5 Fauré C, Lascaux JP, Montagne JP. Le syndrome de Larsen. A propos de trois observations nouvelles. Ann Radiol (Paris) 1976;19:629-36.

6 Renault F, Arthuis M, Rethoré MO, Lafourcade J. Le syndrome de Larsen. Aspects cliniques et génétiques. Arch Fr Pediatr 1982;39:35-8.

7 Henrikson $P$, Ivarsson S, Theander G. The Larsen syndrome and glial proliferation in the brain. Acta Paediatr Scand 1977;66:653-7.

8 Lee PA. Multiple joint dislocations and peculiar facies Am J Dis Child 1973;126:828-30.

9 McKusick V. Mendelian inheritance in man. Catalog of autosomal dominant, autosomal recessive and $X$-linked phenotypes. 5th ed. Baltimore: Johns Hopkins University Press, 1978:566-7.

Correspondence and requests for reprints to Dr P Strisciuglio, Department of Pediatrics, 2nd Faculty of Medicine, University of Naples, Via Pansini 5, 80131 Naples, Italy. 